\title{
Primary Care After Psychiatric Crisis: A Qualitative Analysis
}

Kim S. Griswold, MD, MPH

Luis E. Zayas, PbD

Patricia A. Pastore, FNP

Susan J. Smith, MS

Cbristine M. Wagner, MSW'

Timothy J. Servoss, MS

'The State University of New York at Buffalo, Department of Family Medicine, Family Medicine Research Institute, Buffalo

${ }^{2}$ Center for Mental Health Services Research, George Warren Brown School of Social Work, Washington University, St Louis, Missouri

${ }^{3}$ Department of Psychology, Canisius College, Buffalo, New York

\begin{abstract}
PURPOSE Patients with serious psychiatric problems experience difficulty accessing primary care. The goals of this study were to assess whether care managers improved access and to understand patients' experiences with health care after a psychiatric crisis.
\end{abstract}

METHODS A total of 175 consecutive patients seeking care in a psychiatric emergency department were randomly assigned to an intervention group with care managers or a control group. Brief, semistructured interviews about health care encounters were conducted at baseline and 1 year later. Five raters, using the content-driven, immersion-crystallization approach, analyzed 112 baseline and year-end interviews from 28 participants in each group. The main outcomes were patients' responses about their care experiences, connections with primary care, and integration of medical and mental health care. Scores for physical function and mental function were compared by analysis of variance (ANOVA).

RESULTS At baseline, most participants described negative experiences in receiving care and emphasized the importance of listening, sensitivity, and respect. Fully $71 \%$ of patients in the intervention group said that having a care manager to assist them with primary care connections was beneficial. Patients in the intervention group had significantly better physical and mental function than their counterparts in the control group at 6 months $(P=.03$ for each) but not at 12 months. There was also a trend toward functional improvement over the course of the study in the intervention group.

CONCLUSIONS This analysis suggests that care management is effective in helping patients access primary care after a psychiatric crisis. It provides evidence on and insight into how care may be delivered more effectively for this population. Future work should assess the sustainability of care connections and longer-term patient health outcomes.

Ann Fam Med 2008;6:38-43. DOI: 10.1370/afm.760.

\section{INTRODUCTION}

$\mathrm{P}$ atients with serious mental illness have medical comorbidity and may not receive adequate primary care; they have impaired physical and emotional health and use the emergency department rather than the primary care setting..$^{1-3}$ There is evidence that even if individuals with serious mental illness have a regular source of primary care, they may not access services because of a lack of coordination between mental and medical health care. ${ }^{4,5}$ Primary care is of value to patients with behavioral disorders. In one study, patients with psychiatric disorders viewed primary care as the cornerstone for both their physical and mental health care ${ }_{i}$ they emphasized continuity of care and listening skills as critical components. ${ }^{6}$ Getting connected to the physician, however, may pose a problem for patients with serious mental illness who are emerging from psychiatric crisis. Responsiveness of the treatment system and collaboration between mental health and primary care systems can enhance communication between medical and mental health care professionals and positively affect 
the aftercare of patients discharged from a psychiatric emergency department..$^{7-10}$

Case management interventions for selected populations with serious mental illness, such as the assertive connection team or the patient navigator used in cancer prevention programs, have proven valuable and cost-effective in the community, and are effective in overcoming access barriers and in integrating medical and mental health care services for patients. ${ }^{11-15}$ But we could find no study that looked specifically at qualitative assessment of care management interventions between psychiatric emergency and primary care. This research was part of a mixed-methods study, using a randomized, controlled trial (RCT) design, to investigate the effectiveness of care managers in connecting patients to primary medical care after psychiatric crisis. We used qualitative methods to gain insight about these patients' experiences accessing primary and mental health care, and to better understand patients' responses and perceptions about care managers in the context of access to and initial satisfaction with primary care.

In this article we describe a qualitative analysis of patient interviews regarding their experiences of medical care after a psychiatric emergency visit and during the subsequent year, either with a care manager (intervention group) or without a care manager (control group), along with assessments of function. We expected that many of these psychiatric patients would have had poor experiences within the medical care system, and therefore we (1) documented their experiences $_{i}(2)$ assessed whether patients in the intervention group expressed benefit after having a care manager

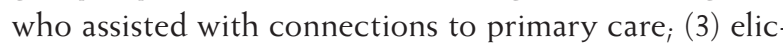
ited patients' perceptions on the concept of integrated care to assess whether views were commensurate with the Institute of Medicine's (IOM's) impetus for a seamless system of care $^{4}$; and (4) performed functional assessments to track changes in physical and mental health function over the study period.

\section{METHODS}

\section{Study Design}

In an institutional review board-approved RCT conducted between 2002 and 2006, 175 consecutive patients seeking care in the psychiatric emergency department of an urban public hospital were recruited, randomized to an intervention or control group through a table of randomized numbers, and followed up for 1 year. The intervention group received care managers who helped them link to medical care, whereas the control group received usual care; selected care manager interventions are shown in
Table 1. Four patients in the control group received case management through the mental health system; these patients were regarded as intervention patients, as their experiences were more in line with those exposed to care management.

A measure of functional assessment, the 36-Item Short Form Healthy Survey (SF-36), ${ }_{1}^{16}$ was administered to all patients at baseline, at the 6-month follow-up, and at the 1-year follow-up (end of study). A brief semistructured interview (Table 2) was conducted concurrently with all trial participants at baseline and 1 year. A total of 112 baseline and 1-year interviews from 56 patients - 28 from each study group-were randomly selected and analyzed until reaching saturation. We integrated qualitative and quantitative approaches at the data collection and interpretation stages following a "concurrent triangulation strategy" to provide a more comprehensive assessment of the care management component and corroborate related findings. ${ }^{17}$

\begin{tabular}{|c|c|c|}
\hline Assistance & Control & Intervention \\
\hline $\begin{array}{l}\text { Assistance with health care insur- } \\
\text { ance application }\end{array}$ & $\mathrm{x}$ & $x$ \\
\hline Provision of peer support & $\mathrm{x}$ & $\mathrm{x}$ \\
\hline $\begin{array}{l}\text { Information on primary care sites } \\
\text { that are federally funded or have } \\
\text { sliding fee scales }\end{array}$ & $\mathrm{x}$ & $\mathrm{x}$ \\
\hline Provision of care manager & & $x$ \\
\hline $\begin{array}{l}\text { Assistance with making primary care } \\
\text { appointments }\end{array}$ & & $\mathrm{x}$ \\
\hline $\begin{array}{l}\text { Assistance with attending primary } \\
\text { care appointments }\end{array}$ & & $\mathrm{x}$ \\
\hline $\begin{array}{l}\text { Identification of travel routes and } \\
\text { public transportation options }\end{array}$ & & $\mathrm{x}$ \\
\hline $\begin{array}{l}\text { Patient education; reinforcement of } \\
\text { teaching from primary care }\end{array}$ & & $\mathrm{x}$ \\
\hline $\begin{array}{l}\text { Ongoing follow-up, including home } \\
\text { visits and mobile outreach }\end{array}$ & & $\mathrm{x}$ \\
\hline $\begin{array}{l}\text { Coordination with mental health } \\
\text { peers to support connections with } \\
\text { community mental health care }\end{array}$ & & $x$ \\
\hline
\end{tabular}

Table 2. Interview Questions Used for Qualitative Analysis

1. How would you describe your current health status in general (ie, body, mind, and soul)?

2. Where do you usually go and whom do you see to get care for your health and wellness concerns? Please describe.

3. How would you describe your experiences (good and/or bad ones) in trying to get the health care you need for both your medical and mental health concerns?

4. What do you think are the main problems with trying to get the health care you need for both your medical and mental health concerns?

5. What does or would it mean to you to have (a) a regular medical doctor? (b) a regular medical doctor who consults with your mental health care professional? 


\section{Data Collection}

Three research staff with expertise in health services research conducted the qualitative interviews, either in person in a private hospital room or by telephone. To standardize interviewing techniques, all interviewers received prestudy and ongoing training in qualitative interviewing and analysis from the medical anthropologist on the research team. Regular team meetings were held to discuss data quality issues. The same interviewer conducted both the baseline and 1-year (study end) interviews for each patient interviewed. Interviewers did not have contact with patients before the study. In-person interviews lasted an average of 30 minutes and were audio-recorded and transcribed for analysis. Telephone interviews tended to be shorter in duration (15 to 20 minutes) and were recorded in shorthand; the shorthand notes were developed into full notes following the interview. The percentage of interviews done in person was greater at study baseline (64\%) than at 1 year $(24 \%)$, but this did not vary by interviewer or group.

\section{Data Analysis}

We analyzed the qualitative and quantitative data separately. Qualitative transcripts were entered into NVivo 2.0 (QSR International, Cambridge, Massachusetts) for data management and analysis. ${ }^{18}$ The multidisciplinary analytic team consisted of the 5 researchers trained in qualitative analysis: a family physician, a medical anthropologist, a nurse-practitioner, a social worker, and an epidemiologist. All 5 analysts reviewed the selected baseline transcripts; 3 analyzed the follow-up interviews with control patients, and 2 analyzed the follow-up interviews with intervention patients. The analysis followed the content-driven, immersion and crystallization approach, consisting of a systematic iterative process of text interpretation and categorization to establish patterns of importance. ${ }^{19,20}$ First, the analysts independently reviewed the transcripts to identify meaningful descriptions or noteworthy statements related to the research questions. They then met to compare preliminary findings and debate interpretations before developing coding strategies through consensus; themes were subsequently derived from the series of coded statements to establish the main findings. Trustworthiness of the analysis was strengthened by the diversity of perspectives that functioned as checks and balances in the analytic process, and through postanalysis transcript searches for conflicting or disconfirming evidence. ${ }^{21}$

To assess patients' function with the SF-36, we followed scoring procedures to create a physical component summary score and a mental component summary score. These 2 measures served as the dependent variables in separate 2-way factorial analyses of variance (ANOVA) with group (intervention vs control) as the between-patients factor and time (baseline, 6 months, and 12 months) as the within-patients factor. In addition to the main effects of time and treatment, the time-by-treatment interaction was of particular interest in this analysis. This analysis yielded trends in functional and health outcomes, which could be triangulated with qualitative findings of perceived benefits of care management and the value of integrated medical and mental health care.

\section{RESULTS}

\section{Patient Characteristics}

Baseline characteristics of the 56 patients whose interviews were analyzed are shown in Table 3 . Two-thirds were male; about half were white and more than onethird were African American. The majority (73\%) had a high school education or less. Nearly $65 \%$ were unemployed, 94\% had annual household incomes of $\$ 20,000$ or less, and $29 \%$ had been homeless at some time. Almost 38\% had more than 1 mental health disorder.

\section{Care Experiences}

As expected, at baseline most patients described negative experiences with both mental and physical health care. Patients talked about difficulties with health care access and insurance. Predictably, access to care was challenging for many. For instance, as some commented, "There are a lot of choices but not a lot of information"; and "It took 2 hours to get the Pap done ... I never went back." Participants expressed frustration about a lack of insurance, for example, stating, "It's like having a finger off your hand when you don't have insurance; something's missing." Patients commented on the difficulty of the process, as in, "I was supposed to recertify [Medicaid] but ... I was working and making too much money"; and "My Medicare ... covers only ER and hospital visits ... it should cover the things you need, which for me is medication and doctor's visits."

Participants' experiences in obtaining health care were also colored by various personal challenges, evident in such comments as, "I stopped going because I'd get depressed"; and "I've had mostly bad [experiences] because of the voices I hear." Experiences were also colored by self-recrimination; for instance, one patient commented, "my head wasn't on straight, ... I blame myself ..."; whereas another asserted, "if the person doesn't go get it, it's their fault."

Another theme pertained to clinician-patient communication issues, specifically, the clinician's ability to listen and explain care recommendations in a way that the patient could understand. For example, comments included, "I talk but they don't hear me..., he wasn't listening to $\mathrm{me}^{\prime}$; and "it's a big scene and it doesn't seem 


\begin{tabular}{|c|c|}
\hline Characteristic & No. (\%) \\
\hline \multicolumn{2}{|l|}{ Sex } \\
\hline Male & $38(67.9)$ \\
\hline Female & $18(32.1)$ \\
\hline \multicolumn{2}{|l|}{ Age, years } \\
\hline$<30$ & $16(28.6)$ \\
\hline $30-39$ & $12(21.4)$ \\
\hline $40-49$ & $15(26.8)$ \\
\hline$\geq 50$ & $13(23.2)$ \\
\hline \multicolumn{2}{|l|}{ Race/ethnicity } \\
\hline African American & $21(37.5)$ \\
\hline White & $27(48.2)$ \\
\hline American Indian & $1(1.8)$ \\
\hline Latino & $2(3.6)$ \\
\hline Other & $5(8.9)$ \\
\hline \multicolumn{2}{|l|}{ Employment } \\
\hline Full time & $5(9.3)$ \\
\hline Self-employed & $1(1.9)$ \\
\hline Part time & $13(24.1)$ \\
\hline Unemployed & $35(64.8)$ \\
\hline \multicolumn{2}{|l|}{ Annual household income } \\
\hline$<\$ 5,000$ & $28(52.8)$ \\
\hline$\$ 5,000-\$ 9,999$ & $15(28.3)$ \\
\hline$\$ 10,000-\$ 20,000$ & $7(13.2)$ \\
\hline$>\$ 20,000$ & $3(5.7)$ \\
\hline \multicolumn{2}{|l|}{ Education } \\
\hline 8th grade or less & $4(7.1)$ \\
\hline Some high school & $14(25.0)$ \\
\hline High school graduate/GED degree & $23(41.1)$ \\
\hline Some college or more & $15(26.8)$ \\
\hline Been homeless & $16(29.0)$ \\
\hline \multicolumn{2}{|l|}{ Mental health disorder } \\
\hline Mood disorder & $21(37.5)$ \\
\hline Adjustment disorder & $8(14.3)$ \\
\hline Psychotic disorder & $22(39.3)$ \\
\hline Substance use disorder & $26(46.4)$ \\
\hline Dual diagnosis & $21(37.5)$ \\
\hline
\end{tabular}

anyone is listening." Another patient noted that "when it comes to dispensing medication, they need to know that our minds are 100 places elsewhere ... we need things explained more."

An additional common theme was respect for patients or lack of it. Several patients mentioned being treated respectfully, for example, stating, "I feel I was taken care of properly in a 'mannerful' way"; and "I've always been treated well, always [with] a smile." Others, however, described experiences of disrespect, as when "the doctors cuss at me because I hadn't taken care of myself."

\section{Care Connections}

Fully 20 (71\%) of the 28 patients in the intervention group indicated that having a care manager to assist them with primary care access was beneficial. One patient mentioned, "I go to the Community Health Center, which you helped me get ... I feel more comfortable that I have a regular doctor. I don't feel so exploited." Another patient also linked with primary care, who had already received a diagnosis of type 2 diabetes mellitus, was reassured: "You have to have a doctor... If you keep skipping around, it's like a hopscotch game"; and "I like that I have a regular doctor ... you're the one who helped me get to see him!" This sentiment was echoed by a patient with chronic back pain, who commented, "I'd say (my health) is excellent because you helped me right away ... having a regular doctor makes me feel at ease"; as well as by another in need of gynecologic care, who stated, "You guys made it easier. ... If I'm sick, I don't have to go to Rite Aid. I have a real doctor that knows my body."

One respondent in particular said at baseline that he hated doctors and thought that having a regular doctor was "bull," but after being connected with primary care admitted "my physical health is good ... I'm in a program called Solutions to Wellness ... it's good to have a regular doctor." Becoming established with a regular physician with the help of care managers resonated with several other patients, who reported, "Oh, it means a lot to me now. I never had one before.... He's a very good doctor"; and "it means there's somebody out there to talk to me, to help me and get my medications from ... it felt good."

In contrast, patients who did not receive care management (the control group) noted their lack of a connection to primary care. These patients commented on what having a regular physician would mean to them: "It would mean a lot because right now I need medical stuff like birth control and to get my asthma checked"; "It would mean a lot because I had unprotected sex ... and now I want to get tested"; "It means a lot because you never know what can happen"; and "It would mean everything to me. To actually talk to someone. Right now I'm in limbo." One respondent also mentioned the impact that having a regular physician might have on the setting used for obtaining care: "... then I wouldn't have to sit in the ER."

\section{Care Integration}

In response to a hypothetical question about the potential value of integrated medical and mental health care (Table 2, question $5 \mathrm{~b}$ ), patients offered favorable opinions, with no differences at baseline or 1 year in responses. The notion of having a regular physician who confers with a mental health care professional 
appealed to many patients. As one observed, "2 places that would be familiar with me, the patient being me." Several felt that communication between these 2 health care professionals might improve overall care: "This would be good ... the doctor would not be speculating ... both ... would know and understand what's going on with my care"; "it's important ... this way they're on the same page on what to do for me"; and "that would be good because my physical health might affect my mental health." Other patients remained unsure about the prospect of having a regular physician who confers with a mental health care professional, saying, "I never needed it"; and "I couldn't answer that ... couldn't imagine." In addition, some patients were concerned about a potential breach of confidentiality from such integration of care, stating, for instance, "I probably would have a problem with that ... it makes me feel weird"; and "I like confidentiality ... some distance ... I want to give information at my own free will."

\section{Functional Outcomes}

At 6 months, relative to control patients, intervention patients had significantly better physical function (SF36 physical component summary score: $F 1,33=5.55$, $P=.03$ ) and mental function (SF-36 mental component summary score: $F 1,33=5.03, P=.03$ ). At 1 year (study end), however, the differences were no longer significant, although there was an overall trend toward functional improvement over the course of the study for the intervention group. The physical health problems in the control and intervention groups were comparable and included type 2 diabetes, hypertension, hyperlipidemia, arthritis, and asthma. ${ }^{22}$

\section{DISCUSSION}

This qualitative work found that over 1 year of followup among patients who had experienced a psychiatric crisis, those in an intervention group with care managers had easier access to primary care and felt it was of benefit to them. As one patient commented, "Having a primary care doctor was like an ace in the hole! It meant security and peace of mind."

This study provides added insight about patients who seek care from the health system with some kind of psychiatric emergency, and the findings support other studies wherein nurse case management was an effective strategy among patients with serious psychiatric problems. It is ideal to establish care connections in the community whereby primary care clinicians provide collaborative and continuous care to patients with mental disorders. ${ }^{12,23-25}$

Related research has documented the importance of linking patients to primary care. In one study, link- age following detoxification produced better patient outcomes. ${ }^{26}$ The benefits of connections to primary care for patients with substance use problems included improvement of overall care, early identification and treatment of conditions recognized by primary care and mental health professionals, and the possibility of improved outcomes of substance abuse treatment. ${ }^{27,28}$ Functional assessment of the patients in our study indicated a trend toward improved physical and mental health summary scores for patients in the intervention group at the 1-year follow-up, which converged with the patients' mostly favorable qualitative assessments of care management. Future work needs to replicate this finding and assess outcomes with extended follow-up periods.

Patients in our sample discussed known barriers to health care at various system levels: patient, care process, and health care system. ${ }^{4}$ They emphasized the importance of good communication, sensitivity, and respect between clinicians and patient. Patients also acknowledged personal challenges to obtaining or accepting medical help. In addition, most study patients lived below the federal poverty level. Although those with Medicaid found it easier to access health care, most faced continued difficulties in maintaining health insurance and coverage for needed psychiatric medications - a particularly important component of their health care.

The concept of an integrated system of medical and mental health care seemed to interest many study participants, as several even recognized the interconnection of physical and mental health. Other patients, however, expressed concerns about such integration, preferring to keep their health issues private. These concerns will need to be addressed in current efforts to bring together disjointed systems of care, as highlighted in the IOM report. ${ }^{4}$

There are several important limitations to this study. Different interviewing modes (in-person vs telephone) may have affected the depth and quality of the information obtained. Interviewers were not blinded to study conditions at baseline or study end, which may have affected their qualitative probing. Patients were quite willing to discuss their health care encounters, nevertheless. Another potential limitation is that this sample may have experienced above-average difficulty with the health care system because most were socioeconomically disadvantaged. Finally, the participants' literacy level, which may have affected their responses to care, was not assessed.

This qualitative analysis supports quantitative findings that care management is effective in helping patients access primary care after a psychiatric crisis, and that for some it makes the difference between finding a regular physician or going without care. 
Firsthand patient accounts of their experiences with and opinions about seeking and obtaining health care are essential feedback in building bridges between disjointed systems of care. Care connections are vital for these patients, many of whom have chronic conditions needing ongoing medical management. Future work should assess the sustainability of care connections and longer-term patient health outcomes.

To read or post commentaries in response to this article, see it online at http://www.annfammed.org/cgi/content/full/6/1/38.

Key words: Primary care; psychiatry; mental health; qualitative research; delivery of health care; patient care management; health services research; vulnerable populations; continuity of care

Submitted July 31, 2006; submitted, revised, July 3, 2007; accepted July 6, 2007.

Acknowledgments: The authors appreciate the collaboration of the Department of Psychiatry, University of Buffalo, and thank Angela Henke for her invaluable assistance.

\section{References}

1. Felker B, Yazel JJ, Short D. Mortality and medical comorbidity among psychiatric patients: a review. Psychiatr Serv. 1996;47(12):1356-1363.

2. Sokal J, Messias E, Dickerson FB, et al. Comorbidity of medical illnesses among adults with serious mental illness who are receiving community psychiatric services. J Nerv Ment Dis. 2004;192(6):421427.

3. De Alba I, Samet JH, Saitz R. Burden of medical illness in drugand alcohol-dependent persons without primary care. Am J Addict. 2004;13(1):33-45.

4. Institute of Medicine. Improving the Quality of Health Care for Mental and Substance-Use Conditions. Quality Chasm Series. Washington, DC: Institute of Medicine; 2006.

5. Levinson Miller C, Druss BG, Dombrowski EA, Rosenheck RA. Barriers to primary medical care among patients at a community mental health center. Psychiatr Serv. 2003;54(8):1158-1160.

6. Lester H, Tritter JQ, Sorohan H. Patients' and health professionals' views on primary care for people with serious mental illness: focus group study. BMJ. 2005;330(7500):1122.

7. Klinkenberg WD, Calsyn RJ. Predictors of receiving aftercare 1, 3, and 18 months after a psychiatric emergency room visit. Psychiatr Q. 1999;70(1):39-51.

8. Katon W, Von Korff M, Lin E, Simon G. Rethinking practitioner roles in chronic illness: the specialist, primary care physician, and the practice nurse. Gen Hosp Psychiatry. 2001;23(3):138-144.

9. Santiago JM, McCall-Perez F, Bachrach LL. Integrated services for chronic mental patients: theoretical perspective and experimental results. Gen Hosp Psychiatry. 1985;7(4):309-315.

10. Mauksch LB, Tucker SM, Katon WJ, et al. Mental illness, functional impairment, and patient preferences for collaborative care in an uninsured, primary care population. J Fam Pract. 2001;50(1):41-47.
11. Bond GR, Salyers MP. Prediction of outcome from the Dartmouth assertive community treatment fidelity scale. CNS Spectr. 2004;9(12):937-942.

12. Rabins PV, Black BS, Roca R, et al. Effectiveness of a nurse-based outreach program for identifying and treating psychiatric illness in the elderly. JAMA. 2000;283(21):2802-2809.

13. Dohan D, Schrag D. Using navigators to improve care of underserved patients: current practices and approaches. Cancer. 2005;104(4):848-855.

14. Sarfaty M, Turner CH, Damotta E. Use of a patient assistant to facilitate medical visits for Latino patients with low health literacy. J Community Health. 2005;30(4):299-307.

15. Lantz PM, Keeton K, Romano L, Degroff A. Case management in public health screening programs: the experience of the National Breast and Cervical Cancer Early Detection Program. J Public Health Manag Pract. 2004;10(6):545-555.

16. Beusterien KM, Steinwald B, Ware JE Jr. Usefulness of the SF-36 Health Survey in measuring health outcomes in the depressed elderly. J Geriatr Psychiatry Neurol. 1996;9(1):13-21.

17. Creswell JW. Research Design: Qualitative, Quantitative, and Mixed Methods Approaches. Thousand Oaks, CA: Sage Publications; 2003.

18. Qualitative Solutions and Research (QSR). NVivo 2.0: Using NVivo in Qualitative Research (Computer Software \& Manual). Melbourne, Australia: QSR International; 2002.

19. Miller W, Crabtree B. Primary care research: a multimethod typology and qualitative road map. In: Crabtree BF, Miller WL, eds. Doing Qualitative Research. Newbury Park, CA: Sage Publications; 1992.

20. Borkan J. Immersion/crystallization. In: Crabtree B, Miller W, eds. Doing Qualitative Research. Thousand Oaks, CA: Sage Publications; 1999.

21. Kuzel A, Like RC. Standards of trustworthiness for qualitative studies in primary care. In: Norton PG, ed. Primary Care Research: Traditional and Innovative Approaches. Newbury Park, CA: Sage Publications; 1991:138-158.

22. Griswold KS, Servoss TJ, Leonard KE, et al. Connections to primary medical care after psychiatric crisis. J Am Board Fam Pract. 2005;18(3):166-172.

23. Hunkeler EM, Meresman JF, Hargreaves WA, et al. Efficacy of nurse telehealth care and peer support in augmenting treatment of depression in primary care. Arch Fam Med. 2000;9(8):700-708.

24. Gask L, Sibbald B, Creed F. Evaluating models of working at the interface between mental health services and primary care. $\mathrm{Br} J \mathrm{Psy}$ chiatry. 1997;170:6-11.

25. Kates N, Craven M, Bishop J. National Conjoint Committee on Mental Health Care: Shared Mental Health Care in Canada-Position Paper. Ottowa, ON: Canada Psychiatric Association and the College of Family Physicians of Canada; 1996.

26. Schwenk TL, Coyne JC, Fechner-Bates S. Differences between detected and undetected patients in primary care and depressed psychiatric patients. Gen Hosp Psychiatry. 1996;18(6):407-415.

27. Samet JH, Friedmann P, Saitz R. Benefits of linking primary medical care and substance abuse services: patient, provider, and societal perspectives. Arch Intern Med. 2001;161(1):85-91.

28. Samet JH, Larson MJ, Horton NJ, Doyle K, Winter M, Saitz R. Linking alcohol- and drug-dependent adults to primary medical care: a randomized controlled trial of a multi-disciplinary health intervention in a detoxification unit. Addiction. 2003;98(4):509-516. 